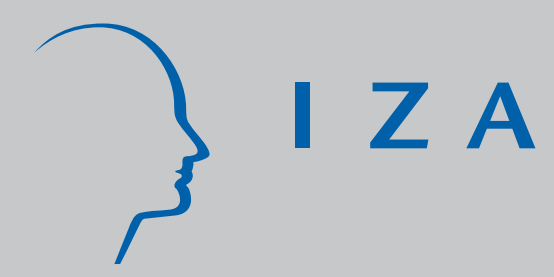

IZA DP No. 928

Does City Structure Affect the Labor Market Outcomes of Black Workers?

Harris Selod

Yves Zenou

November 2003 


\title{
Does City Structure Affect the Labor Market Outcomes of Black Workers?
}

\author{
Harris Selod \\ INRA-LEA and CREST-LEI \\ Yves Zenou \\ IUI, University of Southampton \\ and IZA Bonn
}

\section{Discussion Paper No. 928 \\ November 2003}

\author{
IZA \\ P.O. Box 7240 \\ D-53072 Bonn \\ Germany \\ Tel.: +49-228-3894-0 \\ Fax: +49-228-3894-210 \\ Email: iza@iza.org
}

This Discussion Paper is issued within the framework of IZA's research area Welfare State and Labor Market. Any opinions expressed here are those of the author(s) and not those of the institute. Research disseminated by IZA may include views on policy, but the institute itself takes no institutional policy positions.

The Institute for the Study of Labor (IZA) in Bonn is a local and virtual international research center and a place of communication between science, politics and business. IZA is an independent, nonprofit limited liability company (Gesellschaft mit beschränkter Haftung) supported by Deutsche Post World Net. The center is associated with the University of Bonn and offers a stimulating research environment through its research networks, research support, and visitors and doctoral programs. IZA engages in (i) original and internationally competitive research in all fields of labor economics, (ii) development of policy concepts, and (iii) dissemination of research results and concepts to the interested public. The current research program deals with (1) mobility and flexibility of labor, (2) internationalization of labor markets, (3) welfare state and labor market, (4) labor markets in transition countries, (5) the future of labor, (6) evaluation of labor market policies and projects and (7) general labor economics.

IZA Discussion Papers often represent preliminary work and are circulated to encourage discussion. Citation of such a paper should account for its provisional character. A revised version may be available on the IZA website (www.iza.org) or directly from the author. 
IZA Discussion Paper No. 928

November 2003

\section{ABSTRACT}

\section{Does City Structure Affect the Labor Market Outcomes of Black Workers?*}

In this paper, location choices are driven by households (both blacks and whites) consciously choosing to trade off proximity to neighbors of similar racial backgrounds for proximity to jobs. Because of coordination failures in the location choices, multiple urban equilibria emerge. There is a 'Spatial-Mismatch Equilibrium' in which blacks reside far away from jobs and experience high unemployment rates and a 'Spatial-Matching Equilibrium' in which blacks are closer to jobs and experience lower unemployment rates. Under some reasonable condition, we demonstrate that all workers are better off under the Spatial-Matching Equilibrium, leaving a role for policy intervention.

JEL Classification: J15, R14

Keywords: $\quad$ spatial mismatch, multiple equilibria, racial preferences, social networks, labor discrimination

Corresponding author:

Yves Zenou

The Research Institute of Industrial Economics

Box 5501

11485 Stockholm

Sweden

Email: yvesz@iui.se

\footnotetext{
* We would like to thank the participants of seminars at the universities of Aberdeen, Brussels, Lausanne, Michigan State University and Southampton for helpful comments, in particular Mathias Ho.mann, Kai Konrad, Robin Mason, Juuso Valimaki, Etienne Wasmer and Fabrizio Zilibotti. We are also indebted to Stephen Sheppard and Said Souam for useful suggestions.
} 


\section{Introduction}

Most (American and European) cities exhibit stark and persisting socioeconomic disparities across neighborhoods and racial groups. In particular in the US, segregated black workers residing in inner cities often face lower wages and higher unemployment probabilities than other workers residing elsewhere in the city.

Even though the link between urban segregation and labor market outcomes of ethnic minorities has been extensively debated and studied by social scientists (see, among others, Kain, 1968; Massey and Denton, 1988; Holzer, 1991; Benabou, 1993; Borjas 1995; Wilson, 1996; Cutler and Glaeser, 1997; Topa, 2001), we still do not have a clear understanding of this link. It may be because two seemingly unrelated issues are at stake: the location choices of workers in cities and their consequences in the labor market.

In the present paper, location choices are driven by households (both blacks and whites) consciously choosing to trade off proximity to neighbors of similar racial backgrounds for proximity to jobs. However, while many questions whether minority households can truly choose where to reside with U.S. metropolitan areas (choice constrained by housing discrimination), it is generally assumed that in the absence of locational constraints the resulting spatial equilibrium would conform to that of standard monocentric models, i.e., we would not be able to improve welfare by moving people around, there would be no market failure, and, thus, no role for policy intervention (see e.g. Fujita, 1989). The model presented here essentially contests this proposition, by pointing out that multiple spatial equilibria arise under reasonable assumptions on racial preferences and that one equilibrium is arguable inferior to the other so that there is some role for policy intervention.

To be more precise, we consider three different groups: whites, conformist blacks who abide by the ghetto's norms and thus wish to live among blacks, and status-seeker blacks who abide by the norms of the white majority and thus wish to live close to whites. As stated above, the spatial separation between racial groups does not result from housing discrimination but is caused by the voluntary choices of individuals who desire to interact exclusively with other individuals of their own community. Given the residential structure of the city, there are two main factors that determine job acquisition: labor discrimination and the amount of information workers can gather about jobs through (local) social networks and (local) formal sources of information.

We show that multiple equilibria emerge depending on which equilibrium 
individuals coordinate their residential choices. In the 'Spatial-Mismatch Equilibrium', blacks reside far away from jobs, experience high unemployment rates and have poor social networks. In the 'Spatial-Matching Equilibrium', blacks are close to jobs and experience low unemployment rates whereas whites, who locate further away from jobs, can still face a low unemployment rate because they are not discriminated against. We demonstrate that under some condition, workers are better off under the Spatial-Matching Equilibrium than under the Spatial-Mismatch Equilibrium, confirming various empirical studies that show that spatial mismatch is very harmful to blacks.

We also show that access to jobs does not matter very much for whites (because they are not being discriminated against) nor for status-seeker blacks (because of their local interactions with whites) but does matter very much for conformist blacks. We are also able to highlight the fact that social networks strongly depend on location and physical distance to jobs, which implies that social networks differ across locations and groups.

The remainder of the paper is organized as follows. The model is introduced in the next section. In section 3, we determine the different urban land-use equilibria and the associated labor-market outcomes. In section 4, we compare the two equilibria and discuss some important implications of our model. Section 5 extends the model by explicitly deriving the discrimination behavior of employers and the endogenous wage setting. It also proposes a set of numerical simulations that illustrates the workings of the model. Finally, section 6 concludes.

\section{The model}

Let us consider a continuum of equally productive workers (blacks and whites) ${ }^{1}$ uniformly distributed along a linear and closed city. All land is owned by absentee landlords and all firms are exogenously located in the Business District (BD hereafter). The BD is a unique employment center located at one end of the linear city. In a centralized city, it corresponds to the Central Business District, whereas in a completely decentralized city, it represents suburban employment. We assume that firms only resort to two types of recruitment methods: by word of mouth, or by posting 'want ads' in local newspapers.

\footnotetext{
${ }^{1}$ In this paper, we do not focus on differences in education between blacks and whites. On the contrary, we want to compare their labor market outcomes for a given level of human capital.
} 
This assumption will have important consequences on the amount of locally available information about jobs in each residential district (see subsection 2.2 below). Workers are risk neutral, optimally decide their place of residence between the BD and the other end of the city, and all consume the same amount of land (normalized to 1 for simplicity). Without loss of generality, the density of residential land parcels is taken to be unity, so that there are exactly $x$ units of housing within a distance $x$ from the BD. As mentioned in our introduction and discussed in detail below, there are three groups: two types of blacks respectively denoted by $B S$ (status-seeker blacks) and $B C$ (conformist blacks), and whites denoted by $W$. The sizes of each population group are respectively denoted by $\bar{N}_{B S}, \bar{N}_{B C}$ and $\bar{N}_{W}$, with $\bar{N}_{B S}+\bar{N}_{B C}+\bar{N}_{W} \equiv 1$, so that the second end of the city is at a distance equal to 1 from the BD.

\subsection{Racial preferences and utilities}

In our model, racial preferences play a fundamental role because the desireor reluctance - to interact with other racial groups can influence the relative location of each community in the city. The present subsection discusses our way of modeling such preferences.

As stated in the introduction, residential segregation occurs because individuals prefer to interact exclusively with other individuals of their own community. This assumption may seem provocative but has both theoretical and empirical foundations. From a theoretical point of view, Loury (1999) observes that 'even a mild desire for people to live near members of their own race can lead to a strikingly severe degree of segregation in the aggregate'. This is indeed a well know result in 'preference models' (see the theoretical and empirical studies of Schelling, 1971, Galster, 1990, 2000). In a recent empirical study, Ihlanfeldt and Scafidi (2002) find evidence that racial preferences is a large, if not the main factor that explains housing segregation in Atlanta, Boston, Detroit and Los Angeles. They show that the respective preferences of blacks and whites for the racial composition of their neighborhoods account for $65 \%$ and $9 \%$ of housing segregation in those cities. This is in accordance with the controversial observation that 'segregation is partly - and for most middle-class Afro-Americans, largely - a voluntary phenomenon' (Patterson, 1997). ${ }^{2}$

\footnotetext{
${ }^{2}$ To explain why individuals have such racial preferences is beyond the scope of the present paper. It should be noted however that both majority and minority groups may have reasons to segregate themselves. In particular, it is believed that minority groups may wish
} 
To model this behavior, we assume that there exist costs or benefits associated with living near and interacting with individuals of a different race. The idea is not new in the literature on ghettos (see for instance Cutler and Glaeser, 1997, who present a stylized model in which blacks incur a cost to move into areas where whites are a majority, and whites bear a similar cost to move into mostly black areas). We adopt a fairly similar way of modeling racial preferences. In our model, the further an individual locates from another race group, the fewer contacts the individual is likely to establish with members of that race group. This means that individuals from a given community who seek interracial contacts will value living close to the other community, whereas individuals who prefer to interact exclusively with members of their own group will shun such locations. Thus, depending on their tastes for interracial social interactions, individuals may benefit or suffer from a group-specific externality increasing or decreasing with the distance to the physical frontier between races.

In order to keep the model tractable, we assume that groups always form spatially homogenous communities. In other words, we only focus on equilibria in which all the members of a given community live together and thus do not mix with members of other communities (this is in accordance with real-world cities; see e.g. Table 1 in Borjas, 1998). This is because the aim of this paper is not to explain why segregation occurs (or why only homogenous communities emerge in equilibrium $)^{3}$ but rather to analyze the consequences of urban segregation on labor market outcomes. In this context, what only matters for a white (black) worker in terms of racial preferences is the residential location of the closest black (white) individual.

We will now express the utility functions of workers. To do that, let us consider an individual located in $x$. If this individual is white, we denote by $b_{B}(x)$ the location of the closest black worker from $x$. If this individual is a conformist black or a status-seeker black, we denote by $b_{W}(x)$ the location of the closest white from $x$. Since communities are assumed to be homogenous,

to share a common culture with their neighbors or to interact in their own language (Akerlof, 1997, Akerlof and Kranton, 2000), that they may be prejudiced against whites or may have expectations of unfavorable treatment by whites in white neighborhoods (Ihlanfeldt and Scafidi, 2002) and that clustering together might enable them to mobilize common resources (Yinger, 1985), improving their access to ethnic goods such as food, education or religious service.

${ }^{3}$ The endogenous formation of segregation has been analyzed in the urban economics literature by, among others, Courant and Yinger (1977), Yinger (1976) and surveyed by Fujita (1989, ch.7) and Kanemoto (1980). 
observe that: $(i)$ by definition, the location of the closest black (white) individual is the location of the closest border between communities; (ii) both $b_{B}(x)$ and $b_{W}(x)$ are step functions such that generically $b_{B}^{\prime}(x)=0$ and $b_{W}^{\prime}(x)=0$ wherever these functions are defined and differentiable. This is because two close neighbors share the same closest neighborhood border. Therefore, the respective utility functions for a white, a status-seeker black, and a conformist black worker of employment status $j=U, E$, and location $x$, are given by:

$$
\begin{gathered}
V_{W j}(x)=y_{j}-t x-R(x)+e_{W}\left|x-b_{B}(x)\right| \\
V_{B S j}(x)=y_{j}-t x-R(x)+e_{B S}\left|x-b_{W}(x)\right| \\
V_{B C j}(x)=y_{j}-t x-R(x)+e_{B C}\left|x-b_{W}(x)\right|
\end{gathered}
$$

where $y_{j}$ is the exogenous income of a worker with employment status $j$ ( $y_{E}$ and $y_{U}$ are respectively the wage of the employed and the unemployment benefit, with $\left.y_{E}>y_{U}>0\right), t$ is the commuting cost per unit of distance, $R(x)$ is the land rent at a distance $x$ from the $\mathrm{BD}$ and $e_{i}$ measures racial preferences.

The following comments are in order. First, we have assumed that, irrespective of race, all workers are paid the same wage. This is because all workers have the same education level and are equally productive. We will treat the case of endogenous wages in section 5. Second, we have assumed that the unemployed and the employed bear the same commuting cost per unit of distance. This assumption can be justified by considering that, when unemployed, workers still have to go to the BD in order to shop. Even though it is not essential to our model, this assumption simplifies the analysis. Third, in our formulation, the racial externality incurred by a worker of one community is expressed through the distance to the other community. Therefore, racial preferences are captured through the fact that individuals may want to live far from or close to the other community so as to interact or avoid contact with members of the other group. We assume that all whites want to live far away from blacks and that some blacks (labeled 'conformist blacks') want to live far away from whites. In our framework, this requires $e_{W}>0$ and $e_{B C}>0$. For these two types of workers, it is easy to see that when the distance to the other community increases, utility increases, reflecting the disutility of interracial contacts with neighbors. This is the case because some black workers may not 'trust' people from other communities, especially whites, especially when they have been historically discriminated against. In a similar way, whites may not 'trust' blacks because of some traumatic experiences such as crime or fear of crime (see Alesina and La Ferrara, 2001, for an interesting study on trust 
and racial mixing). To the contrary, we assume that there is another group of blacks (labeled 'status-seeker blacks') who would like to live close to whites, implying $e_{B S}<0$. It is then easy to see that, for status-seeker blacks, utility increases with proximity to the boundary between communities, reflecting the benefit of living close to the other community.

These differences in behavior among blacks have sociological justifications: it has been observed that when a community is or has been socially excluded from a dominant group, some will identify with the dominant culture whereas others may reject it, even if it involves low economic returns for the latter subgroup (Akerlof and Kranton, 2000). ${ }^{4}$ To summarize, in our model, some black workers are 'status-seekers' $\left(e_{B S}<0\right)$ abiding by the white group's norms and trying to develop social contacts with whites, whereas others are 'conformists' willing to maintain a group culture (like e.g. black nationalism), which implies social distance between themselves and whites $\left(e_{B C}>0\right)$. In the urban space, the former are willing to live close to whites $\left(e_{B S}<0\right)$ whereas the latter are less sensitive to the issue of integration and value residing far away from the white community $\left(e_{B C}>0\right)$.

\subsection{Social networks and the job acquisition rate}

At any moment, workers can either be employed or unemployed. We assume that changes in the employment status (employment versus unemployment) are governed by a continuous-time Markov process. In our framework, there is a two-stage procedure to obtain a job. First, workers must have a job contact with a firm and then a job match with this firm (as for example in Pissarides, 2000, ch.6). The first stage requires that unemployed workers acquire information about jobs (this process will be detailed below) in order to establish a contact. In the second stage, the match is automatically realized for whites, whereas it is realized with probability $m<1$ for any black worker. This is because we assume that there are two types of firms in the economy: nondiscriminating firms (in proportion $m$ ) and discriminating firms (in proportion

\footnotetext{
${ }^{4}$ Empirical studies confirm such a behavioral split between blacks. For instance, Bledsoe et al. (1995) show that inner-city blacks and those living in predominantly black neighborhoods show stronger racial solidarity towards blacks as a whole than black suburbanites and black residents of racially-mixed neighborhoods. In a similar perspective, Cutler and Glaeser (1997) observe that it is skilled minorities who actually come into contact with whites, whereas unskilled minorities are left behind in segregated areas. This suggests that the different inclinations could be attributable to differences in skills, maybe because skilled individuals may benefit more from integration than unskilled individuals.
} 
$1-m)$. So when a black worker has a contact with a firm, this job contact is transformed into a job match only if the firm does not discriminate against blacks. The probability $1-m$ can represent the prejudices of employers who dislike associating with black workers (see Becker, 1957). The labor discrimination against black workers, especially in cities, is well documented. See in particular Raphael, Stoll and Holzer (2000) and Holzer and Reaser (2000).

We assume that job contacts randomly occur at an endogenous rate $\theta_{i}$ for a worker of type $i=W, B S, B C$, while the exogenous job separation rate is $\delta .^{5}$ In this context, the job acquisition rate (that is the transition rate from unemployment to employment) is the product of the job contact rate and the probability of a job match. Since whites always transform a job contact into a job match, their job acquisition rate is equal to their job contact rate $\theta_{W}$. For blacks, the job contact rate must be multiplied by $m$ (the probability that the contacted firm is not discriminating). In this context, the expected duration of employment is given by $1 / \delta$ for all workers whereas the expected durations of unemployment differ among groups and amount to $1 / \theta_{W}, 1 / m \theta_{B S}$ and $1 / m \theta_{B C}$ for whites, status-seeker blacks and conformist blacks respectively. It then follows that a white worker spends a fraction $\theta_{W} /\left(\theta_{W}+\delta\right)$ of his lifetime employed and a fraction $\delta /\left(\theta_{W}+\delta\right)$ of his lifetime unemployed. For statusseeker blacks and conformist blacks these fractions are respectively given by $m \theta_{B S} /\left(m \theta_{B S}+\delta\right)$ and $\delta /\left(m \theta_{B S}+\delta\right)$, and $m \theta_{B C} /\left(m \theta_{B C}+\delta\right)$ and $\delta /\left(m \theta_{B C}+\delta\right)$.

Let us now determine the job contact rate $\theta_{i}$, which is group-specific. It is given by: ${ }^{6}$

$$
\theta_{i}=\mu+\lambda s_{i}-\beta \bar{x}_{i} \quad i=W, B S, B C
$$

where $\mu>0$ is the common information about jobs available to anyone (independently of race or space), $s_{i}$ denotes the (endogenous) local social network of a worker of type $i$, and $\bar{x}_{i}$ is the (endogenous) average distance to the employment center for workers of type $i . \lambda$ and $\beta$ are positive parameters that measure the respective impacts of social networks and distance to jobs on the job contact rate.

In our framework, the higher the job contact rate, the shorter an unemployed worker is expected to wait before experiencing a job contact. In the

\footnotetext{
${ }^{5}$ The higher $\theta_{i}$ and $\delta$, the shorter the expected periods of time before a job contact or a job destruction. For instance, if $\theta_{i}$ tends towards infinity, then the unemployed workers of type $i$ never have to wait before establishing a contact with a firm. If $\delta$ tends to zero then the duration of employment tends to infinity.

${ }^{6}$ Here also the assumption that each community lives in a racially homogenous neighborhood is important to derive $\theta_{i}$.
} 
specification we have chosen, the job contact rate only depends on the amount of information workers can gather about job opportunities in the BD. Formula (4) assumes that a given level of information is available to anyone in the city and that this level of information may be altered locally, through social networks or formal sources of information. Indeed, the bulk of information about jobs is obtained locally, through employed friends or local newspapers. In other words, besides the common knowledge factor, there are two ways of learning about jobs: either employed workers hear about the job on the workplace and transmit this information to all their residential unemployed neighbors, or the unemployed directly read about job opportunities in the newspapers published in their area of residence. It should be clear that none of these channels involve commuting to the $B D$ since, in our framework, it is information that reaches the neighborhood and workers only commute to the $\mathrm{BD}$ in order to work and shop. This is why the job acquisition rate $\theta_{i}$ is group-specific and the probability of finding a job is the same for all unemployed workers within a given group $i$ (what matters is the neighborhood of residence and not the individual's particular location within that neighborhood).

Let us now present in detail the two channels through which information about jobs can be gathered. The first channel operates via social networks which are built upon local connections. The local connections that individuals from a given group $i$ can use to find a job are measured by $s_{i}$ which we assume to be a positive function of that group's employment rate $1-u_{i}$ (or equivalently a negative function of the unemployment rate $u_{i}$ ). In other words, when the unemployment rate is high among a particular group, individuals of that group have few connections that can refer them to jobs and their social network is poor (Calvo-Armengol, 2000, Calvo-Armengol and Zenou, 2001, Montgomery, 1991, Mortensen and Vishwanath, 1994, Topa, 2001). ${ }^{7}$ In our model, only the employed can transmit information about jobs and there are negative externalities associated with unemployment: a group with a high proportion of unemployed workers offers few connections to jobs, so that members of that group have few chances to find a job. In this respect, the employment rate measures the quality of a group's social network since the probability to find a job increases with the proportion of one's neighbors who currently hold a job.

\footnotetext{
${ }^{7}$ Resorting to word of mouth and newspaper ads are two major job search methods that are used by young males (see Holzer, 1987, 1988). Word of mouth, in particular, seems to be of crucial importance: almost 70 percent of the jobs obtained by white workers and almost 60 percent of those obtained by black workers are found by checking with relatives or friends or through direct application without referral (Holzer, 1987).
} 
These negative externalities associated with unemployment can be compared to those of the standard matching model (Pissarides, 2000) in which the presence of other unemployed workers lowers the job acquisition rate because of search or congestion externalities.

As far as whites are concerned, individuals only use (local) connections with other whites so that their social network is simply defined by:

$$
s_{W}=1-u_{W}
$$

For blacks, there are two cases depending on their residential location in the city. If they reside far away from whites, then they only benefit from their own connections to jobs and thus:

$$
s_{B}=1-u_{B}
$$

If, to the contrary, blacks reside in the same neighborhood as whites (or, more accurately in our model, in an adjacent neighborhood) then they benefit from their own connections to jobs and also from part of the social network of whites (because of the local interactions between the two neighboring groups). In this case, the social network of blacks depends on their own employment rate but also on that of their white neighbors, so that we have:

$$
s_{B}=\alpha\left(1-u_{W}\right)+(1-\alpha)\left(1-u_{B}\right)
$$

with $0<\alpha<1$. This local externality causes the employment rate in the black neighborhood to be positively affected by the employment rate in the adjacent white area. However, depending on the value of $\alpha$, blacks can benefit more or less from whites' connections to jobs. If for example $\alpha$ is close to 1 , then blacks benefit almost entirely from the social network of their white neighbors, so that they have access to a local social network which is almost as good as that of whites. To the contrary, a very low $\alpha$ indicates that, because of racial prejudices, there are very few contacts between blacks and whites living in adjacent neighborhoods, so that the social network spillover between the two groups is very limited. The existence of such externalities across neighborhoods is empirically verified. For instance, using Census Tract data for Chicago in 1980 and 1990, Topa (2001) finds a significantly positive amount of social interactions across neighboring tracts, especially for areas with a high proportion of less educated workers and/or minorities.

The second way workers can learn about jobs involves local formal sources of information. What we have in mind here is the amount of information 
conveyed by ads in local newspapers. Obviously, this type of information is available to all workers residing in the same neighborhood since they can all buy the same local newspaper. Since employers tend to post more ads in newspapers that cover areas adjacent to their firms, we assume that the quantity of information available in each district decreases with the district's distance to the $B D$. This is why, in (4), we have considered that the job acquisition rate of type- $i$ workers negatively depends on $\bar{x}_{i}$, the workers' average distance to the BD - which should be considered as a measure of the district's distance to firms - As a matter of fact, several empirical studies on job search confirm that distance to jobs deteriorates the information one has on job opportunities and that job accessibility is crucial to get a job (see for example Rogers, 1997, Stoll, 1999). In particular, Ihlanfeldt (1997) has shown that Atlanta's inner-city residents are less able to identify the location of suburban employment centers than suburbanites and thus, have less information on those jobs. Turner (1997) has shown that, in Detroit's suburbs, firms which resort to local recruitment methods have very few inner-city black applicants. In our model, firms only use local recruitment methods (such as local newspapers or relying on word-of-mouth communication), which emphasizes the adverse effect of physical distance to jobs.

To sum up, the job contact rate strongly depends on the availability of information in each district. In our formulation, workers of a specific group obtain information about jobs through their social networks (measured by the number of employed workers in their community) but also through the quantity of formal information about jobs which reaches their neighborhood (measured by their district's distance to the BD).

\subsection{The labor market}

As stated above, changes in the employment status of a worker of type $i=$ $W, B S, B C$ are governed by a time continuous Markov process in which $\theta_{i}$ is the (group-specific) job contact rate and $\delta$ is the job destruction rate. In steady state, flows into and out of unemployment are equal. Therefore, for whites, we have:

$$
u_{W}=\frac{\delta}{\theta_{W}+\delta}
$$

whereas for status-seeker and conformist blacks, we respectively obtain:

$$
u_{B S}=\frac{\delta}{m \theta_{B S}+\delta}
$$




$$
u_{B C}=\frac{\delta}{m \theta_{B C}+\delta}
$$

where $u_{i}$ denotes the unemployment rate of workers of type $i=W, B S, B C$. Observe from (8), (9) and (10), that the steady state unemployment and employment rates correspond to the respective fractions of time a worker remains unemployed and employed over his infinite lifetime. Equations (8), (9) and (10) can also be interpreted as the probabilities a type- $i$ worker will be unemployed or employed in steady state.

We are now able to calculate the expected utilities of each group. To do that, we assume perfect capital markets with a zero interest rate, ${ }^{8}$ which enable workers to smooth their income over time as they enter and leave unemployment: workers save while employed and draw down on their savings when out of work. At any moment, the disposable income of a type- $i$ worker is thus equal to that worker's average income over the job cycle. Therefore, the expected utility of a worker of type $i=W, B S, B C$ residing in $x$ is given by:

$$
E V_{i}=\left(1-u_{i}\right) V_{i E}(x)+u_{i} V_{i U}(x)
$$

where $V_{i E}$ and $V_{i U}$ are given by (1), (2) or (3), and $u_{i}$ is determined by (8), (9) or (10).

To write this expected utility, we have assumed that, because workers are able to smooth their income over time, a worker's residential location remains fixed as he enters and leaves unemployment. This is more realistic than assuming that changes in employment status involve changes in residential location.

\section{$3 \quad$ The different equilibria}

In equilibrium, all workers of the same type reach the same utility level: $v_{W}$, $v_{B S}$ and $v_{B C}$ for whites, status-seeker blacks, and conformist blacks respectively. Therefore, the bid rent of a white worker residing at a distance $x$ from

\footnotetext{
${ }^{8}$ When there is a zero interest rate, workers have no intrinsic preference for the present so that they only care about the fraction of time they spend employed and unemployed. Therefore, the expected utilities are not state dependent. For example, since a white worker spends a fraction $\theta_{W} /\left(\theta_{W}+\delta\right)$ of his lifetime employed and a fraction $\delta /\left(\theta_{W}+\delta\right)$ unemployed, his average income is equal to $\frac{\theta_{W}}{\theta_{W}+\delta} y_{E}+\frac{\delta}{\theta_{W}+\delta} y_{U}$. The same analysis applies for status-seeker and conformist blacks.
} 
the BD is equal to: ${ }^{9}$

$$
\Psi_{W}\left(x, v_{W}\right)=\frac{\theta_{W}}{\theta_{W}+\delta}\left(y_{E}-y_{U}\right)+y_{U}-t x+e_{W}\left|x-b_{B}(x)\right|-v_{W}
$$

whereas those of status-seeker and conformist blacks are respectively given by:

$$
\begin{aligned}
& \Psi_{B S}\left(x, v_{B S}\right)=\frac{m \theta_{B S}}{m \theta_{B S}+\delta}\left(y_{E}-y_{U}\right)+y_{U}-t x+e_{B S}\left|x-b_{W}(x)\right|-v_{B S} \\
& \Psi_{B C}\left(x, v_{B C}\right)=\frac{m \theta_{B C}}{m \theta_{B C}+\delta}\left(y_{E}-y_{U}\right)+y_{U}-t x+e_{B C}\left|x-b_{W}(x)\right|-v_{B C}
\end{aligned}
$$

In equilibrium, (absentee) landlords allocate land to the highest bids. Since we assume that groups always form spatially homogenous communities and since bid rents are all linear in $x$ (recall that generically $b_{B}^{\prime}(x)=0$ and $b_{W}^{\prime}(x)=$ 0 ), it is then easy to verify that six different equilibrium land-use configurations can arise depending on the relative ranking of whites $(W)$, status-seeker blacks $(B S)$ and conformist blacks $(B C)$ in the city. However, we show that under a reasonable assumption, only two equilibria can be sustained: Equilibrium 1, in which, moving outward from the $\mathrm{BD}$, we have the location of the following groups: $W, B S, B C$ (see Figure 1) and Equilibrium 2, in which, starting from the $\mathrm{BD}$, we have: $B C, B S, W$ (see Figure 2). We will refer to Equilibrium 1 as the Spatial-Mismatch Equilibrium since, under that equilibrium, blacks reside far away from jobs. ${ }^{10}$ To the contrary, Equilibrium 2 corresponds to a situation in which blacks reside close to jobs and that we will call the Spatial-Matching Equilibrium.

\footnotetext{
${ }^{9}$ The bid rent is a standard concept in urban economics. It indicates the maximum land rent that a worker located at a distance $x$ from the BD is ready to pay in order to achieve utility level $v$.

${ }^{10}$ The spatial mismatch hypothesis, first formulated by Kain (1968), states that, residing in urban segregated areas distant from and poorly connected to major centers of employment growth, black workers face strong geographic barriers to finding and keeping well-paid jobs. See the surveys by Holzer (1991), Kain (1992), Ihlanfeldt and Sjoquist (1998) and Gobillon et al. (2003).
} 
Proposition 1 Assume that ${ }^{11}$

$$
e_{B C}<\left|e_{B S}\right|<e_{W}
$$

Then, we have multiple equilibria in which either the Spatial-Mismatch Equilibrium (Equilibrium 1) or the Spatial-Matching Equilibrium (Equilibrium 2) occur.

Proof. See Appendix 1.

The following comments are in order. First, observe that assuming $e_{B C}<$ $\left|e_{B S}\right|<e_{W}$ means that whites are more eager to isolate themselves from blacks than status-seeker blacks to have contacts with whites $\left(e_{W}>\left|e_{B S}\right|\right)$, while status-seeker blacks are more eager to have contacts with whites than conformist blacks to isolate themselves from whites $\left(\left|e_{B S}\right|>e_{B C}\right)$. This is in accordance with the findings of Cutler, Glaeser and Vigdor (1999) who find that whites are more likely to oppose living in a majority-black neighborhood than blacks in either a majority-black or white neighborhood. The reasons why only Equilibrium 1 and Equilibrium 2 can be sustained under assumption (14) are quite easy to understand. The assumption that $e_{B C}<\left|e_{B S}\right|$ is used to rule out the two urban configurations in which whites locate in between status-seeker blacks and conformist blacks, so that status-seeker blacks and conformist blacks must locate on the same side of whites. Moreover, the two other urban configurations in which conformist blacks locate in between whites and status-seeker blacks can never be sustained since the two black groups would always prefer to switch locations (since $e_{B C}>0$ and $e_{B S}<0$ ). It follows, using $e_{W}>\left|e_{B S}\right|$, that status-seeker blacks must always locate in between whites and conformist blacks, so that only Equilibrium 1 and Equilibrium 2 can exist.

Second, recall that we have focused on spatially homogenous communities. Relaxing this assumption would lead to more equilibria than those stated in Proposition 1 since communities would be able to form subgroups in the urban space. Recall nevertheless that the focus of our model is to explain the adverse effect of distance to jobs on labor market outcomes rather than to explain the endogenous formation of spatially homogenous neighborhoods. Thus, since

\footnotetext{
${ }^{11}$ We also assume that $\left|e_{B S}\right|<t<e_{W}$. These are just technical conditions that are not necessary to obtain the results of Proposition 1 (see Appendix 1). The first condition $\left(t<e_{W}\right)$ ensures that the bid rent of whites is increasing in Equilibrium 2 and the second condition $\left(\left|e_{B S}\right|<t\right)$ guarantees that the bid rents of all blacks are decreasing in both equilibria.
} 
status-seeker and conformist blacks always live in adjacent areas, there exists only one border between racial communities for each equilibrium. This implies that $b_{B}^{k}(x)$ and $b_{W}^{k}(x)$ are independent of $x$ and equal to a constant $b^{k}$ (where $b^{k}$ denotes the unique border location in Equilibrium $k=1,2$ ).

Third, let us now discuss the existence of multiple equilibria. Assumption (14) guarantees that $e_{W}>\left|e_{B S}\right|$ which makes both Equilibria 1 and 2 sustainable (otherwise status-seeker blacks would always outbid whites for their locations and the urban configuration would not be sustainable). The reason we have multiple equilibria is because the driving force behind the location of communities is racial preferences since commuting costs do not discriminate between blacks and whites (the commuting cost per unit of distance is the same for all races). Therefore, multiple equilibria emerge since what matters is only the desire of workers to live or not to live with other individuals of their communities. This is because distance to jobs equally affects the location decision of each community and thus does not favor any of the two urban configurations. In this context, which equilibrium will prevail only depends on the coordination of workers. Observe that both equilibria exhibit racially homogeneous neighborhoods. This is indeed a well documented phenomenon in US cities. In 1979, for example, the average black lived in a neighborhood that was $63.6 \%$ black, even though blacks formed only $14.9 \%$ of the population (Borjas, 1998). In the last Census (1990), the figures were similar (Cutler, Glaeser and Vigdor, 1999).

Finally, note that in both Equilibria 1 and 2, it is status-seeker blacks who reside close to whites and thus benefit from the social network of whites in addition to their own connections to jobs. To the contrary, conformist blacks live far away from whites and only benefit from their own social network. This implies that (6) and (7) can now be rewritten as:

$$
\begin{gathered}
s_{B C}=1-u_{B C} \\
s_{B S}=\alpha\left(1-u_{W}\right)+(1-\alpha)\left(1-u_{B S}\right)
\end{gathered}
$$

We are now able to determine the job contact rate of each community. Using (5), (15) and (16), we can rewrite (4) for Equilibrium $k=1,2$ as:

$$
\begin{gathered}
\theta_{W}^{k}=\mu+\lambda\left(1-u_{W}^{k}\right)-\beta \bar{x}_{W}^{k} \\
\theta_{B S}^{k}=\mu+\lambda\left[\alpha\left(1-u_{W}^{k}\right)+(1-\alpha)\left(1-u_{B S}^{k}\right)\right]-\beta \bar{x}_{B S}^{k} \\
\theta_{B C}^{k}=\mu+\lambda\left(1-u_{B C}^{k}\right)-\beta \bar{x}_{B C}^{k}
\end{gathered}
$$


Observe that $\lambda$ measures the marginal gain in social network following a rise in employment rate(s) whereas $\beta$ accounts for the marginal loss of formal information associated with distance to the BD. We impose the following condition to guarantee that $\theta_{i}^{k}$ is always strictly positive:

$$
\mu>\beta
$$

In this context, the border $b^{k}$ between blacks and whites in equilibrium $k$ is such that: $b^{1}=\bar{N}_{W}$ while $b^{2}=\bar{N}_{B} \equiv \bar{N}_{B C}+\bar{N}_{B S}$.

\subsection{The Spatial-Mismatch Equilibrium (Equilibrium 1)}

The slopes of the different bid rents are given in Appendix 1 by (46), (47) and (48) and the resulting urban equilibrium is represented by Figure 1. In this urban configuration, whites live close to the BD whereas status-seeker blacks and conformist blacks live further away. Whites are attracted to the BD for two reasons: to save on commuting costs and to be as far as possible from the border distance $b^{1} \equiv \bar{N}_{W}$ with blacks. Therefore, the equilibrium land rent decreases from the BD to $\bar{N}_{W}$ in order for white workers to obtain the same utility level $v_{W}$ whatever their location between 0 and $\bar{N}_{W}$. Status-seeker blacks are also attracted to the BD to be close to jobs and close to whites so that the equilibrium land rent also decreases between $\bar{N}_{W}$ and $\bar{N}_{W}+\bar{N}_{B S}$. For conformist blacks, there are in fact two opposite forces: on one hand, they would like to be close to the BD in order to save on commuting costs; on the other hand, they would like to be as far as possible from whites and thus from the BD. Since $t>e_{B C}$, the former effect dominates the latter and land rent also decreases between $\bar{N}_{W}+\bar{N}_{B S}$ and 1 .

Because blacks differ in their racial preferences, those among blacks who value most interacting with other blacks will prefer to reside relatively further away from the white community. This is why, in equilibrium, when whites reside close to the employment center, conformist blacks locate far away from jobs. We refer to Equilibrium 1 as a Spatial-Mismatch Equilibrium since blacks are far away from jobs and, as we will see, they experience high unemployment rates.

\section{[Insert Figure 1 here]}

We are now able to give a formal definition of the market equilibrium (i.e. an equilibrium in both land and labor markets). ${ }^{12}$

\footnotetext{
${ }^{12}$ The population constraints are trivially defined since the density of individuals is one
} 
Definition 1 A Spatial-Mismatch Equilibrium (Equilibrium 1) is a 6-uple $\left(v_{W}^{1 *}, v_{B S}^{1 *}, v_{B C}^{1 *}, u_{W}^{1 *}, u_{B S}^{1 *}, u_{B C}^{1 *}\right)$ such that:

$$
\begin{gathered}
\Psi_{W}\left(\bar{N}_{W}, v_{W}^{1 *}\right)=\Psi_{B S}\left(\bar{N}_{W}, v_{B S}^{1 *}\right) \\
\Psi_{B S}\left(\bar{N}_{W}+\bar{N}_{B S}, v_{B S}^{1 *}\right)=\Psi_{B C}\left(\bar{N}_{W}+\bar{N}_{B S}, v_{B C}^{1 *}\right) \\
\Psi_{B C}\left(1, v_{B C}^{1 *}\right)=0 \\
u_{W}^{1}=\frac{\delta}{\theta_{W}^{1 *}+\delta} \\
u_{B S}^{1}=\frac{\delta}{m \theta_{B S}^{1 *}+\delta} \\
u_{B C}^{1}=\frac{\delta}{m \theta_{B C}^{1 *}+\delta}
\end{gathered}
$$

Equations (21)-(23) reflect equilibrium conditions in the land market (see Figure 1). Equation (21) states that, in the land market, at the border $\bar{N}_{W}$ between whites and status-seeker blacks, bid rents must be equal. Equation (22) says that at the border $\bar{N}_{W}+\bar{N}_{B S}$ between status-seeker blacks and conformist blacks, bid rents must also be equal. Equation (23) means that, at the other end of the city (in $x=1$ ), the bid rent of the most peripheral conformist black worker must be equal to the agricultural land rent (normalized to 0 for simplicity). Equations (24)-(26) express the unemployment rate for each type of workers in which the $\theta$ s are defined by (17), (18) and (19).

Since workers are uniformly distributed in the urban space, it should be clear that:

$$
\begin{gathered}
\bar{x}_{W}^{1 *}=\frac{\bar{N}_{W}}{2} \\
\bar{x}_{B S}^{1 *}=\bar{N}_{W}+\frac{\bar{N}_{B S}}{2} \\
\bar{x}_{B C}^{1 *}=1-\frac{\bar{N}_{B C}}{2}
\end{gathered}
$$

In Appendix 2, we show that all unemployment rates are uniquely determined and are given by (55), (56) and (57). Solving equations (21)-(23) and using (27)-(29) yields the following equilibrium utilities:

$$
\begin{gathered}
v_{W}^{1 *}=\left(1-u_{W}^{1 *}\right)\left(y_{E}-y_{U}\right)+y_{U}-t+e_{B S} \bar{N}_{B S}+e_{B C} \bar{N}_{B C} \\
v_{B S}^{1 *}=\left(1-u_{B S}^{1 *}\right)\left(y_{E}-y_{U}\right)+y_{U}-t+e_{B S} \bar{N}_{B S}+e_{B C} \bar{N}_{B C}
\end{gathered}
$$

everywhere in the city. 


$$
v_{B C}^{1 *}=\left(1-u_{B C}^{1 *}\right)\left(y_{E}-y_{U}\right)+y_{U}-t+e_{B C}\left(1-\bar{N}_{W}\right)
$$

It is now interesting to compare the different unemployment rates and utility levels. We have:

Proposition 2 In the Spatial-Mismatch Equilibrium (Figure 1),

(i) Communities that live closer to jobs have lower unemployment rates:

$$
u_{W}^{1 *}<u_{B S}^{1 *}<u_{B C}^{1 *}
$$

In particular, whites live close to jobs, have the lowest unemployment rate and experience the shortest unemployment spells.

(ii) Blacks who value most interacting with other blacks (conformist blacks) live further away from jobs, have a higher unemployment rate, experience longer unemployment spells than status-seeker blacks.

Proof. See Appendix 3.

In this equilibrium, it is clear that whites and conformist blacks are respectively the most and the less favored group. Indeed, whites have a very good access to jobs (because they are closest to jobs), are not discriminated against, and benefit from a good social network. To the contrary, conformist blacks have a very bad access to jobs, have a poor social network (in particular because they reside far away from whites), and are discriminated against. Therefore, in this equilibrium, the place where conformist blacks live can be viewed as a ghetto: unemployment is rampant and peer pressure (to conform to the ghetto's norms and accept adverse racial preferences) has negative effects on those who are sensitive to it. These results are partly based on the fact that information about jobs can only be acquired locally, either through social networks (employed friends), or via formal sources of information (local newspapers). In this respect, conformist blacks are totally isolated from jobs, both physically and through their local contacts, and have very little information on job opportunities in the BD. The situation is different for status-seeker blacks who do not live in the ghetto but seek contacts with whites. They are less isolated from jobs, both physically and because they have contacts with whites. 


\subsection{The Spatial-Matching Equilibrium (Equilibrium 2)}

In this urban configuration, the slopes of bid rents are given by (49), (50) and (51) in Appendix 1 and the resulting urban equilibrium is described by Figure 2. Conformist blacks live close to the BD, whereas status-seeker blacks and whites live further away. We refer to Equilibrium 2 as a Spatial-Matching Equilibrium since blacks now reside close to jobs and, as we will see, both blacks and whites experience relatively low unemployment rates.

\section{[Insert Figure 2 here]}

We have:

Definition 2 A Spatial-Matching Equilibrium (Equilibrium 2) is a 6-uple $\left(v_{B C}^{2 *}, v_{B S}^{2 *}, v_{W}^{2 *}, u_{B C}^{2 *}, u_{B S}^{2 *}, u_{W}^{2 *}\right)$ such that:

$$
\begin{gathered}
\Psi_{B C}\left(\bar{N}_{B C}, v_{B C}^{2 *}\right)=\Psi_{B S}\left(\bar{N}_{B C}, v_{B S}^{2 *}\right) \\
\Psi_{B S}\left(\bar{N}_{B C}+\bar{N}_{B S}, v_{B S}^{2 *}\right)=0 \\
\Psi_{W}\left(\bar{N}_{B C}+\bar{N}_{B S}, v_{W}^{2 *}\right)=0 \\
u_{W}^{2}=\frac{\delta}{\theta_{W}^{2 *}+\delta} \\
u_{B S}^{2}=\frac{\delta}{m \theta_{B S}^{2 *}+\delta} \\
u_{B C}^{2}=\frac{\delta}{m \theta_{B C}^{2 *}+\delta}
\end{gathered}
$$

The interpretation of these equations are similar to that of (21)-(26) in the case of Equilibrium 1 (see the previous subsection). Since workers are uniformly distributed in the urban space, we have:

$$
\begin{gathered}
\bar{x}_{B C}^{2 *}=\frac{\bar{N}_{B C}}{2} \\
\bar{x}_{B S}^{2 *}=\bar{N}_{B C}+\frac{\bar{N}_{B S}}{2} \\
\bar{x}_{W}^{2 *}=\left(1-\frac{\bar{N}_{W}}{2}\right)
\end{gathered}
$$

In Appendix 2, we show that unemployment rates are uniquely determined and are given by (58), (59) and (60). 
Solving the land market conditions (33)-(35) and using (39)-(41), we come up with the following equilibrium utilities:

$$
\begin{gathered}
v_{B C}^{2 *}=\left(1-u_{B C}^{2 *}\right)\left(y_{E}-y_{U}\right)+y_{U}-t \bar{N}_{B}+\left(e_{B C}-e_{B S}\right) \bar{N}_{B S} \\
v_{B S}^{2 *}=v_{B S}^{2 *}=\left(1-u_{B S}^{2 *}\right)\left(y_{E}-y_{U}\right)+y_{U}-t \bar{N}_{B} \\
v_{W}^{2 *}=\left(1-u_{W}^{2 *}\right)\left(y_{E}-y_{U}\right)+y_{U}-t \bar{N}_{B}
\end{gathered}
$$

We then obtain the following result:

Proposition 3 In the Spatial-Matching Equilibrium (Figure 2), unemployment rates cannot be ranked. However,

(i) If $e_{W} \bar{N}_{W}-e_{B S} \bar{N}_{B S}-e_{B C} \bar{N}_{B C}>t\left(1+\bar{N}_{B S}\right)$, then whites living far away from jobs pay on average higher land rents than blacks residing at the vicinity of the $B D$.

(ii) Even though status-seeker blacks are further away from jobs than conformist blacks, they can have a lower unemployment rate than conformist blacks because they reside close to whites and therefore benefit from their social network.

(iii) Even though whites are the furthest away from jobs, they can experience the lowest unemployment rate when they are sufficiently favored by employers (because of racial discrimination against blacks).

Proof. See Appendix 4.

First, condition $(i)$ guarantees that the average land rent paid by whites is strictly greater than the land rent paid by blacks close to the BD. This condition is obviously satisfied whenever there is a sufficiently large number of whites, which is the case of most US cities. As we will see in the next section, this equilibrium aims to describe cities such as New York or Philadelphia in which blacks residing close to the city center pay low land rents whereas whites living in the suburbs face expensive land values. Moreover, it is easy to see that, in this equilibrium, whites are ready to pay a very high land rent in order to separate themselves from blacks. This may be one of the explanations of high land prices in American residential suburbs. Finally, one of the main results in this proposition is to show that access to jobs is more crucial to blacks than to whites (which is in accordance with the spatial-mismatch literature). 
Indeed, an equilibrium in which whites are the furthest away from jobs can still have that whites have the lowest unemployment rate in the city (if $m$ is sufficiently low). This is because whites always transform a job contact into a job match (since they are not discriminated against at all). Because of their advantage in terms of labor-market discrimination, whites can easily find a job even if they reside far away from jobs. In other words, for high levels of labor discrimination, whites may benefit from a much better socialnetwork than blacks, even if they are physically isolated from jobs. To the contrary the social networks of blacks are strongly connected to their physical distance to jobs. However, if there are strong social network spillovers across adjacent neighborhoods, then, for status-seeker blacks, proximity to the white community may be even more important than proximity to jobs.

\section{Discussion and implications}

\subsection{Comparison between the two equilibria}

Since our model leads to multiple equilibria (Proposition 1), it is quite natural to compare the utilities of agents between the different urban configurations. This involves comparing gains and losses associated with variations in permanent income, transportation costs, and land consumption. Even though analytical comparisons do not enable us to systematically rank these two equilibria, it is quite easy to show that, under a condition on parameters, all workers are better off under Equilibrium 2 than under Equilibrium 1. We have indeed:

\section{Proposition 4 If}

$$
t \bar{N}_{W}-e_{B C} \bar{N}_{B C}-e_{B S} \bar{N}_{B S}>y_{E}-y_{U}
$$

then all workers are better off under the Spatial-Matching Equilibrium (Equilibrium 2) than under the Spatial-Mismatch Equilibrium (Equilibrium 1).

Proof. See Appendix 5.

Proposition 4 states that if blacks are sufficiently keen on interacting with whites, i.e. status-seekers are very eager to have contacts with whites $\left(e_{B S}\right.$ sufficiently negative) and conformists are not too conformist ( $e_{B C}$ small enough), then workers are better off under the Spatial-Matching Equilibrium (Equilibrium 2) than under the Spatial-Mismatch Equilibrium (Equilibrium 1). 
The intuition runs as follows. In our model, racial preferences (as well as transport costs) are completely capitalized in land rents. Comparing the two equilibria, condition (45) guarantees that reductions in land rents more than compensate possible losses in permanent income or that increases in land rents do not completely offset possible gains in permanent income. Conformist blacks are better off under the Spatial-Matching Equilibrium (Equilibrium 2) because they are much less unemployed than under the Spatial-Mismatch Equilibrium (Equilibrium 1) and because, even if they reside closer to jobs, the increase in land rent is quite limited. Whites are better off even though their unemployment rate is higher because, residing far away from jobs, they now face lower land rents. The same intuition applies to status-seeker blacks.

\subsection{How realistic are these urban equilibria?}

Let us now describe in more detail our two equilibria and show that they exhibit some common features with US cities. The first equilibrium, the SpatialMismatch Equilibrium, is typical of many decentralized US cities where most jobs are created in the suburbs and where blacks reside close to the city center. Figure 1bis illustrates this case by flipping the city so that our BD corresponds to a suburban business district that concentrates all jobs. To the contrary, the second equilibrium, the Spatial-Matching Equilibrium, is typical of more centralized US cities where jobs are created in the city center and where blacks live close to jobs. In fact, our two equilibria could correspond to what Glaeser et al. (2000) have labeled 'new cities' (Equilibrium 1) and 'old cities' (Equilibrium 2). ${ }^{13}$ Indeed, in 'new cities'-like e.g. Atlanta, Houston, Los Angeles or Phoenix - Glaeser et al. (2000) find that rich workers (mainly whites) tend to locate in the suburbs (close to jobs), whereas poor workers (mainly blacks) reside in the vicinity of the historical city center (far away from jobs). To the contrary, in 'old cities' - like e.g. Boston, Chicago, New York or Philadelphia, Glaeser et al. (2000) highlight a more complex urban configuration: rich workers do not necessarily live close to jobs and many poor workers (especially blacks) are likely to be living in the city center (close to jobs). For our purpose, the main lesson to be derived from the distinction between 'new' and 'old' cities is that it highlights significant differences in the degree of spatial

\footnotetext{
${ }^{13}$ New cities' are MSAs which did not rank in terms of population among the twelve largest MSAs in 1900, but do rank among them in 1990. 'Old cities' are MSAs which were already among the twelve most populated agglomerations in 1900 and are still among them in 1990 (see Glaeser et al., 2000).
} 
mismatch (see Pugh, 1998, who categorizes different metropolitan areas according to the severity of the mismatch). For instance, Atlanta (a 'new city') has been shown to present spatial features that are 'strongly consistent with the assumptions underlying the spatial mismatch hypothesis: a majority black central city, high rates of segregation, and high rates of entry-level job decentralization' (Ihlanfeldt and Sjoquist, 1998). ${ }^{14}$ By contrast, Chicago (an 'old city') has less spatial mismatch because of job opportunities within city limits, particularly in its central business district (Pugh, 1998).

\section{[Insert Figure 1bis here]}

The distinction between the two types of cities may thus be quite crucial. In particular, our model predicts that all else being equal blacks living in cities in which they are poorly connected to jobs (presumably 'new cities') should experience worse labor-market outcomes than blacks residing in cities in which minorities have better spatial and social connections to jobs (presumably 'old cities'). However, our model also suggests that, even in 'old' cities, blacks residing closer to jobs may nevertheless experience a higher unemployment rate than whites and even other blacks that live further away from jobs.

\section{Concluding remarks}

This paper has emphasized the role of labor discrimination, access to jobs, and social networks in explaining the high unemployment rates among urban blacks in the US. Indeed, we believe that these are three crucial factors that have a significant impact on employment by affecting their frequency of contact with employers and their probability of transforming this contact into a job match. In our model, workers endogenously chose their location by trading off commuting costs and racial preferences, leading to multiple equilibria.

An important lesson to be derived from this model is that urban segregation can be a voluntary phenomenon even if it implies very adverse outcomes on the labor market. If some blacks value social interactions within their own group and, because of that, are ready to segregate themselves by residing far

\footnotetext{
${ }^{14}$ In 1960, 40\% of metropolitan area residents in Atlanta lived in the city center, whereas in 1996, the proportion had fallen to $11.6 \%$. As far as racial segregation is concerned, the 1990 Census recorded that while the Atlanta MSA was $70 \%$ white, the city of Atlanta was $70 \%$ black. As much as $65 \%$ of the region's whites and as low as $18 \%$ of the region's blacks lived in the nothern suburbs of that city.
} 
away from jobs, then they will experience longer unemployment spells and higher unemployment rates. This is amplified by their poor social networks and the fact that blacks are discriminated against in the labor market. This makes them more dependent on proximity to jobs than whites. In this context, being close to jobs is indeed the main way minorities can gather information about jobs, whereas this is not the case for whites. Moreover, social networks are localized, so that blacks living far away from whites know fewer employed people who can refer them to jobs. In other terms, blacks who reside in segregated black ghettos do not benefit from local interactions with whites who have better social networks, which all the more reduces their chances to find a job. All these results are robust when wages and the level of discrimination are endogenous.

Another important message of our model lies with the existence of multiple urban equilibria and their implications for society. Indeed, in single equilibrium models and in the absence of locational constraints or market failures, it is generally assumed that the spatial equilibrium is efficient so that one would not be able to improve welfare by moving people around. In our model, even though we do not have any locational constraints nor market failures, the existence of multiple equilibria contests this view since the urban equilibrium in which minorities reside close to job opportunities is likely to dominate the other one. Thus, this crucial feature of the model which can explain why cities may exhibit different spatial structures also leaves some room for policy intervention. The issue of how a local government can induce workers to coordinate better their residential choices is an important issue and clearly deserves further research.

\section{References}

[1] Akerlof, G. (1997), "Social distance and social decisions", Econometrica, 65, 1005-1027.

[2] Akerlof, G. and Kranton, R. (2000), "Economics and identity", Quarterly Journal of Economics, 115, 715-753.

[3] Alesina, A. and E. La Ferrara (2001), "Who trusts others?", Journal of Public Economics, 85, 207-234.

[4] Becker, G.S. (1957), The Economics of Discrimination, Chicago: Chicago University Press. 
[5] Benabou, R. (1993), "Workings of a city: location, education, and production", Quarterly Journal of Economics, 108, 619-52.

[6] Bledsoe, T., Welch, S., Sigelman, L. and M. Combs (1995), "Residential context and racial solidarity among African Americans", American Journal of Political Science, 39, 434-458.

[7] Borjas, G. J. (1995), "Ethnicity, neighborhoods, and human capital externalities", American Economic Review, 85, 365-390.

[8] Borjas, G. J. (1998), "To ghetto or not to ghetto: Ethnicity and residential segregation", Journal of Urban Economics, 44, 228-253.

[9] Calvo-Armengol, A. (2000), "Job contact networks", Unpublished manuscript, Universitat Pompeu Fabra.

[10] Calvo-Armengol, A. and Y. Zenou (2001), "Job matching, social network and word-of-mouth communication”, CEPR Discussion Paper Series 2797.

[11] Courant, P.N. and J. Yinger (1977), "On models of racial prejudices and urban residential structure", Journal of Urban Economics, 4, 272-291.

[12] Cutler, D. M. and E. L. Glaeser (1997), "Are ghettos good or bad?", Quarterly Journal of Economics, 112, 827-872.

[13] Cutler, D., Glaeser, E.L. and J.L. Vigdor (1999), "The rise and decline of the American gheto", Journal of Political Economy, 107, 455-506.

[14] Fujita, M. (1989), Urban Economic Theory, Cambridge: Cambridge University Press.

[15] Galster, G. (1990), "White flight from racially integrated neighborhoods in the 1970s: the Cleveland experience", Urban Studies, 27, 385-399.

[16] Galster, G. (2000), "Identifying neighborhood thresholds: An empirical exploration", Housing Policy Debate, 11, 701-732.

[17] Glaeser, E.L., Kahn, M. and J. Rappaport (2000), "Why do the poor live in cities?", NBER Working Paper Series No. 7636.

[18] Gobillon, L., Selod, H. and Y. Zenou (2003), "Spatial mismatch: From the hypothesis to the theories", Unpublished manuscript, University of Southampton. 
[19] Holzer H. J. (1991), "The spatial mismatch hypothesis: What has the evidence shown?", Urban Studies, 28, 105-122.

[20] Holzer, H. (1987), "Informal job search and black youth unemployment", American Economic Review, 77, 446-452.

[21] Holzer, H. (1988), "Search method used by unemployed youth", Journal of Labor Economics, 6, 1-20.

[22] Holzer, H. and J. Reaser (2000), "Black applicants, black employees, and urban labor market policy", Journal of Urban Economics, 48, 365-387.

[23] Ihlanfeldt, K. and B. Scafidi (2002), "Black self-segregation as a cause of housing segregation. Evidence from the multi-city study of urban inequality", Journal of Urban Economics, 51, 366-390.

[24] Ihlanfeldt, K. (1997), "Information on the spatial distribution of job opportunities within Metropolitan Areas", Journal of Urban Economics, 41, 218-242.

[25] Ihlanfeldt, K.R. and D.L. Sjoquist (1998), "The spatial mismatch hypothesis: a review of recent studies and their implications for welfare reform", Housing Policy Debate, 9, 849-892.

[26] Kain, J.F. (1968), "Housing segregation, negro employment, and Metropolitan decentralization", Quarterly Journal of Economics, 82, 175197.

[27] Kain J. F. (1992), "The spatial mismatch hypothesis: Three decades later", Housing Policy Debate, 3, 371-460.

[28] Kanemoto, Y. (1980), Theories of Urban Externalities, Amsterdam: North Holland.

[29] Loury, G. C. (1999) "Social exclusion and ethnic groups: The challenge to economics", paper presented at the Annual World Bank Conference on Development Economics, Washington, D.C.

[30] Massey, D.S. and N.A. Denton (1988), "Suburbanization and segregation in U.S. Metropolitan Areas", American Journal of Sociology, 94, 592-626.

[31] Montgomery, J. (1991), "Social networks and labor-market outcomes: Toward an economic analysis", American Economic Review, 81, 1408-1418. 
[32] Mortensen, D.T. and T. Vishwanath (1994), "Personal contacts and earnings. It is who you know!", Labour Economics, 1, 187-201.

[33] O'Reagan, K. and J. Quigley (1998), "Where youth live: economic effects of urban space on employment prospects", Urban Studies, 35, 1187-1205.

[34] Patterson, O. (1997) The Ordeal of Integration: Progress and Resentment in America's "Racial" Crisis. New York: Civitas/Counterpoint.

[35] Pissarides, C.A. (2000), Equilibrium Unemployment Theory, 2nd edition, Cambridge: MIT Press.

[36] Pugh, M. (1998), "Barriers to work: the spatial divide between jobs and welfare recipients in metropolitan areas", Washington, DC: The Brookings Institution.

[37] Raphael, S., M.A. Stoll and H. Holzer, (2000), "Are suburban firms more likely to discriminate against African-Americans?", Journal of Urban Economics, 48, 485-508.

[38] Rogers C. (1997), "Job search and unemployment duration: implications for the spatial mismatch hypothesis", Journal of Urban Economics, 42, 109-132.

[39] Schelling, T. (1971), "Dynamic models of segregation", Journal of Mathematical Sociology, 1, 143-186.

[40] Stoll, M. (1999), "Spatial hob search, spatial mismatch, and the employment and wages of racial and ethnic groups in Los Angeles", Journal of Urban Economics, 46, 129-155.

[41] Topa, G. (2001), "Social interactions, local spillovers and unemployment", Review of Economic Studies, 68, 261-295.

[42] Turner, S. (1997), "Barriers to a better break: Employers discrimination and spatial mismatch in Metropolitan Detroit", Journal of Urban Affairs, 19, 123-141.

[43] Wilson, W. (1996), When Work Disappears: The World of the New Urban Poor, New York: Alfred A. Knopf.

[44] Yinger, J. (1976), "Racial prejudice and racial residential segregation in an urban model, Journal of Urban Economics, 3, 383-396. 
[45] Yinger, J. (1995), Closed Doors, Opportunities Lost: The Continuing Cost of Housing Discrimination, New York: Russel Sage Foundation. 


\section{A Appendix}

\section{A.1 Appendix 1}

$\underline{\text { Proof of Proposition 1: }}$

Since groups are assumed to form spatially homogenous communities and since bid-rent functions are linear (recall that generically $b_{B}^{\prime}(x)=0$ and $b_{W}^{\prime}(x)=0$ ), there are only six possible urban configurations depending on the relative locations of the three groups: $W$ (Whites), $B S$ (Status-Seeker Blacks), $B C$ (Conformist Blacks) within the urban space.

- Equilibrium 1, in which, moving outward from the BD, we have the location of the following groups: $W, B S, B C$;

- Equilibrium 2: $B C, B S, W$;

- Equilibrium 3: $B S, W, B C$;

- Equilibrium 4: $B C, W, B S$;

- Equilibrium 5: $W, B C, B S$;

- Equilibrium 6: $B S, B C, W$.

Observe that all these configurations exhibit only one border between black and white communities, except for configurations 3 and 4 which exhibit two such borders.

The aim of this proof is twofold. First, we show that under (14), only equilibria 1 and 2 can exist. Then, we show that we always have multiple equilibria in which either Equilibrium 1 or 2 can occur.

Let us first show that under (14), only equilibria 1 and 2 can exist. Two observations can be made:

First, throughout this proof, we assume that $e_{W}>t, e_{B C}<t$ and $\left|e_{B S}\right|<t$. These are just technical conditions that are not necessary for the proof but allows us to have plausible economic results.

Second, to determine an equilibrium configuration with heterogeneous workers, it is necessary to rank bid rents in order of relative steepness (see Fujita, 1989). Since bid rents are always linear with respect to $x$ (see (11), (12) and (13)), the ranking of bid rents is thus straightforward. 


\section{(a) Equilibrium 3}

Comparing the bid rents of conformist and status-seeker blacks, it is easy to verify that for Equilibrium 3 to be sustained, it must be that $e_{B C}>\left|e_{B S}\right|$. This obviously contradicts (14) and thus Equilibrium 3 is ruled out.

\section{(b) Equilibrium 4}

Similarly, it is easy to verify that for Equilibrium 4 to be sustained, it must also be that $e_{B C}>\left|e_{B S}\right|$. This obviously contradicts (14) and thus Equilibrium 3 is also ruled out.

\section{(c) Equilibrium 5}

It is easy to verify that for Equilibrium 5 to be sustained, it must be that $e_{B C}<e_{B S}$. This is by definition impossible since $e_{B C}>0$ and $e_{B S}<0$.

\section{(d) Equilibrium 6}

It is also easy to verify that for Equilibrium 5 to be sustained, it must be that $e_{B C}<e_{B S}$. As previously, this is by definition impossible since $e_{B C}>0$ and $e_{B S}<0$.

So far, we have shown that under assumption (14), equilibria 3, 4, 5 and 6 cannot exist. Therefore, if an equilibrium exists, it is either Equilibrium 1 or Equilibrium 2. For each of these two equilibria, we will first show that all bid rents are decreasing before stating the conditions under which the equilibrium can be sustained. Then we will prove the second part of the proposition, i.e. that we have multiple equilibria.

\section{(e) Equilibrium 1}

Using (11), (12) and (13), we have:

$$
\begin{gathered}
\frac{\partial \Psi_{W}\left(x, v_{W}^{1}\right)}{\partial x}=-e_{W}-t<0 \\
\frac{\partial \Psi_{B S}\left(x, v_{B S}^{1}\right)}{\partial x}=e_{B S}-t<0 \\
\frac{\partial \Psi_{B C}\left(x, v_{B C}^{1}\right)}{\partial x}=e_{B C}-t<0
\end{gathered}
$$

In this equilibrium, all bid rents are decreasing. Now, for Equilibrium 1 to exist, it must be that:

$$
\frac{\partial \Psi_{W}\left(x, v_{W}^{1}\right)}{\partial x}<\frac{\partial \Psi_{B S}\left(x, v_{B S}^{1}\right)}{\partial x}<\frac{\partial \Psi_{B C}\left(x, v_{B C}^{1}\right)}{\partial x}
$$


This is always true under assumption (14).

\section{(f) Equilibrium 2}

Using (11), (12) and (13),we have:

$$
\begin{gathered}
\frac{\partial \Psi_{B C}\left(x, v_{B C}^{2}\right)}{\partial x}=-e_{B C}-t<0 \\
\frac{\partial \Psi_{B S}\left(x, v_{B C}^{2}\right)}{\partial x}=-e_{B S}-t<0 \\
\frac{\partial \Psi_{W}\left(x, v_{W}^{2}\right)}{\partial x}=e_{W}-t>0
\end{gathered}
$$

In this equilibrium, both bid rents of blacks are decreasing but the bid rent of whites is increasing. For Equilibrium 2 to hold, we must have:

$$
\frac{\partial \Psi_{B C}\left(x, v_{B C}^{2}\right)}{\partial x}<\frac{\partial \Psi_{B S}\left(x, v_{B S}^{2}\right)}{\partial x}<\frac{\partial \Psi_{W}\left(x, v_{W}^{2}\right)}{\partial x}
$$

This is again always true under assumption (14). This implies that, under assumption (14) both equilibria prevail.

\section{A.2 Appendix 2}

We want to show that, in Equilibrium 1, unemployment rates are uniquely determined. Equations (24)-(26) can be rewritten as:

$$
\begin{gathered}
\lambda\left(u_{W}^{1 *}\right)^{2}-\left(\delta+\mu+\lambda-\beta \bar{N}_{W} / 2\right) u_{W}^{1 *}+\delta=0 \\
\lambda m(1-\alpha)\left(u_{B S}^{1 *}\right)^{2}-\left[\delta+\mu m+\lambda m-\beta m\left(\bar{N}_{W}+\bar{N}_{B S} / 2\right)-\lambda \alpha m u_{W}^{1 *}\right] u_{B S}^{1 *}+\delta=0 \\
\lambda m\left(u_{B C}^{1 *}\right)^{2}-\left[\delta+\mu m+\lambda m-\beta m\left(1-\bar{N}_{B C} / 2\right)\right] u_{B C}^{1 *}+\delta=0
\end{gathered}
$$

Using (20), it is easy to verify that all the discriminants of these seconddegree equations are positive and calculations show that, for each equation, only one solution is comprised between 0 and 1 whereas the other one is always greater than 1. Unemployment rates in Equilibrium 1 are thus uniquely determined and given by:

$$
\begin{gathered}
u_{W}^{1 *}=\frac{\left(\delta+\mu+\lambda-\beta \bar{N}_{W} / 2\right)-\sqrt{\Delta_{W}^{1}}}{2 \lambda} \\
u_{B S}^{1 *}=\frac{\left[\delta+\mu m+\lambda m-\beta m\left(\bar{N}_{W}+\bar{N}_{B S} / 2\right)-\lambda \alpha m u_{W}^{1 *}\right]-\sqrt{\Delta_{B S}^{1}}}{2 \lambda m(1-\alpha)}
\end{gathered}
$$




$$
u_{B C}^{1 *}=\frac{\left[\delta+\mu m+\lambda m-\beta m\left(1-\bar{N}_{B C} / 2\right)\right]-\sqrt{\Delta_{B C}^{1}}}{2 \lambda m}
$$

Let us now show that unemployment rates are uniquely determined in Equilibrium 2 as well. Using exactly the same demonstration as in Equilibrium 1 (mutatis mutandis), it is easy to verify that, using (20), there exists a unique unemployment rate for each group $i=W, B S, B C$ given by:

$$
\begin{gathered}
u_{B C}^{2 *}=\frac{\left(\delta+\mu m+\lambda m-\beta m \bar{N}_{B C} / 2\right)-\sqrt{\Delta_{B C}^{2}}}{2 \lambda m} \\
u_{B S}^{2 *}=\frac{\left[\delta+\mu m+\lambda m-\beta m\left(\bar{N}_{B C}+\bar{N}_{B S} / 2\right)-\lambda \alpha m u_{W}^{2 *}\right]-\sqrt{\Delta_{B S}^{2}}}{2 \lambda m(1-\alpha)} \\
u_{W}^{2 *}=\frac{\left[\delta+\mu+\lambda-\beta\left(1-\bar{N}_{W} / 2\right)\right]-\sqrt{\Delta_{W}^{2}}}{2 \lambda}
\end{gathered}
$$

\section{A.3 Appendix 3}

$\underline{\text { Proof of Proposition } 2}$

(i) It is straightforward to see that whites have the lowest unemployment rate in the city since they are closest to jobs $\left(\bar{x}_{W}^{1 *}<\bar{x}_{B S}^{1 *}<\bar{x}_{B C}^{1 *}\right)$ and are not discriminated against. From (4), this implies that they have the lowest unemployment rate in the city and thus the best social network of all communities. As for status-seeker blacks, they are closer to jobs than conformist blacks $\left(\bar{x}_{B S}^{1 *}<\bar{x}_{B C}^{1 *}\right)$ and, besides, have access to the social network of whites (according to (16)). Status-seeker blacks are thus less unemployed than conformist blacks. It follows that $u_{W}^{1 *}<u_{B S}^{1 *}<u_{B C}^{1 *}$.

(ii) We have shown in $(i)$ that conformist blacks experience the highest unemployment rate in the city.

\section{A.4 Appendix 4}

\section{Proof of Proposition 3}

Unemployment rates cannot be ranked because distance to jobs, social networks and the discrimination parameter may act as opposite forces in (4). 
Indeed, whites are not discriminated against but now live the furthest away from jobs $\left(\bar{x}_{W}^{2 *}>\bar{x}_{B S}^{2 *}>\bar{x}_{B C}^{2 *}\right)$. Similarly, status-seeker blacks are further from jobs than conformist blacks $\left(\bar{x}_{B S}^{2 *}>\bar{x}_{B C}^{2 *}\right)$ but may benefit from the social network of whites to the extent that it compensates for their adverse locations.

(i) Using the slopes of the bid rents, it is straightforward to verify that

$$
R^{2}(1)>R^{2}(0) \Leftrightarrow e_{W} \bar{N}_{W}-e_{B S} \bar{N}_{B S}-e_{B C} \bar{N}_{B C}>t
$$

and that

$$
\begin{gathered}
{\left[R^{2}(1)+R^{2}\left(\bar{N}_{B S}+\bar{N}_{B C}\right)\right] / 2>\left[R^{2}(0)+R^{2}\left(\bar{N}_{B C}\right)\right] / 2} \\
\Leftrightarrow e_{W} \bar{N}_{W}-2 e_{B S} \bar{N}_{B S}-e_{B C} \bar{N}_{B C}>t\left(1+\bar{N}_{B S}\right) .
\end{gathered}
$$

Clearly, $e_{W} \bar{N}_{W}-e_{B S} \bar{N}_{B S}-e_{B C} \bar{N}_{B C}>t\left(1+\bar{N}_{B S}\right)$ implies both of these conditions.

(ii) The result is immediate by comparing $\theta_{W}^{2 *}, \theta_{B S}^{2 *}$ and $\theta_{B C}^{2 *}$.

(iii) The result is immediate by comparing $\theta_{W}^{2 *}, \theta_{B S}^{2 *}$ and $\theta_{B C}^{2 *}$.

\section{A.5 Appendix 5}

\section{Proof of Proposition 4}

We want to show that all workers are better off under Equilibrium 2 than under Equilibrium 1. Using (30)-(32) and (42)-(44), we easily obtain:

$$
\begin{gathered}
v_{W}^{2 *}-v_{W}^{1 *}=\left(u_{W}^{1 *}-u_{W}^{2 *}\right)\left(y_{E}-y_{U}\right)+t \bar{N}_{W}-e_{B S} \bar{N}_{B S}-e_{B C} \bar{N}_{B C} \\
v_{B C}^{2 *}-v_{B C}^{1 *}=\left(u_{B C}^{1 *}-u_{B C}^{2 *}\right)\left(y_{E}-y_{U}\right)+t \bar{N}_{W}-e_{B S} \bar{N}_{B S}-e_{B C} \bar{N}_{B C} \\
v_{B S}^{2 *}-v_{B S}^{1 *}=\left(u_{B S}^{1 *}-u_{B S}^{2 *}\right)\left(y_{E}-y_{U}\right)+t \bar{N}_{W}-e_{B S} \bar{N}_{B S}-e_{B C} \bar{N}_{B C}
\end{gathered}
$$

Since unemployment rates are always between 0 and 1 , the difference in unemployment rates is always between -1 and 1 . In particular, we have that:

$$
\begin{array}{r}
u_{W}^{1 *}-u_{W}^{2 *}>-1 \\
u_{B C}^{1 *}-u_{B C}^{2 *}>-1 \\
u_{B S}^{1 *}-u_{B S}^{2 *}>-1
\end{array}
$$


and thus

$$
\begin{aligned}
\left(u_{W}^{1 *}-u_{W}^{2 *}\right)\left(y_{E}-y_{U}\right) & >-\left(y_{E}-y_{U}\right) \\
\left(u_{B C}^{1 *}-u_{B C}^{2 *}\right)\left(y_{E}-y_{U}\right) & >-\left(y_{E}-y_{U}\right) \\
\left(u_{B S}^{1 *}-u_{B S}^{2 *}\right)\left(y_{E}-y_{U}\right) & >-\left(y_{E}-y_{U}\right)
\end{aligned}
$$

Therefore, using (45), we have:

$$
\begin{aligned}
\left(u_{W}^{1 *}-u_{W}^{2 *}\right)\left(y_{E}-y_{U}\right) & >-\left(y_{E}-y_{U}\right)>-\left(t \bar{N}_{W}-e_{B C} \bar{N}_{B C}-e_{B S} \bar{N}_{B S}\right) \\
\left(u_{B C}^{1 *}-u_{B C}^{2 *}\right)\left(y_{E}-y_{U}\right) & >-\left(y_{E}-y_{U}\right)>-\left(t \bar{N}_{W}-e_{B C} \bar{N}_{B C}-e_{B S} \bar{N}_{B S}\right) \\
\left(u_{B S}^{1 *}-u_{B S}^{2 *}\right)\left(y_{E}-y_{U}\right) & >-\left(y_{E}-y_{U}\right)>-\left(t \bar{N}_{W}-e_{B C} \bar{N}_{B C}-e_{B S} \bar{N}_{B S}\right)
\end{aligned}
$$

which implies that

$$
\begin{array}{r}
t \bar{N}_{W}-e_{B C} \bar{N}_{B C}-e_{B S} \bar{N}_{B S}+\left(u_{W}^{1 *}-u_{W}^{2 *}\right)\left(y_{E}-y_{U}\right)>0 \\
t \bar{N}_{W}-e_{B C} \bar{N}_{B C}-e_{B S} \bar{N}_{B S}+\left(u_{B C}^{1 *}-u_{B C}^{2 *}\right)\left(y_{E}-y_{U}\right)>0 \\
t \bar{N}_{W}-e_{B C} \bar{N}_{B C}-e_{B S} \bar{N}_{B S}+\left(u_{B S}^{1 *}-u_{B S}^{2 *}\right)\left(y_{E}-y_{U}\right)>0
\end{array}
$$

and thus

$$
\begin{aligned}
v_{W}^{2 *}-v_{W}^{1 *} & >0 \\
v_{B C}^{2 *}-v_{B C}^{1 *} & >0 \\
v_{B S}^{2 *}-v_{B S}^{1 *} & >0
\end{aligned}
$$




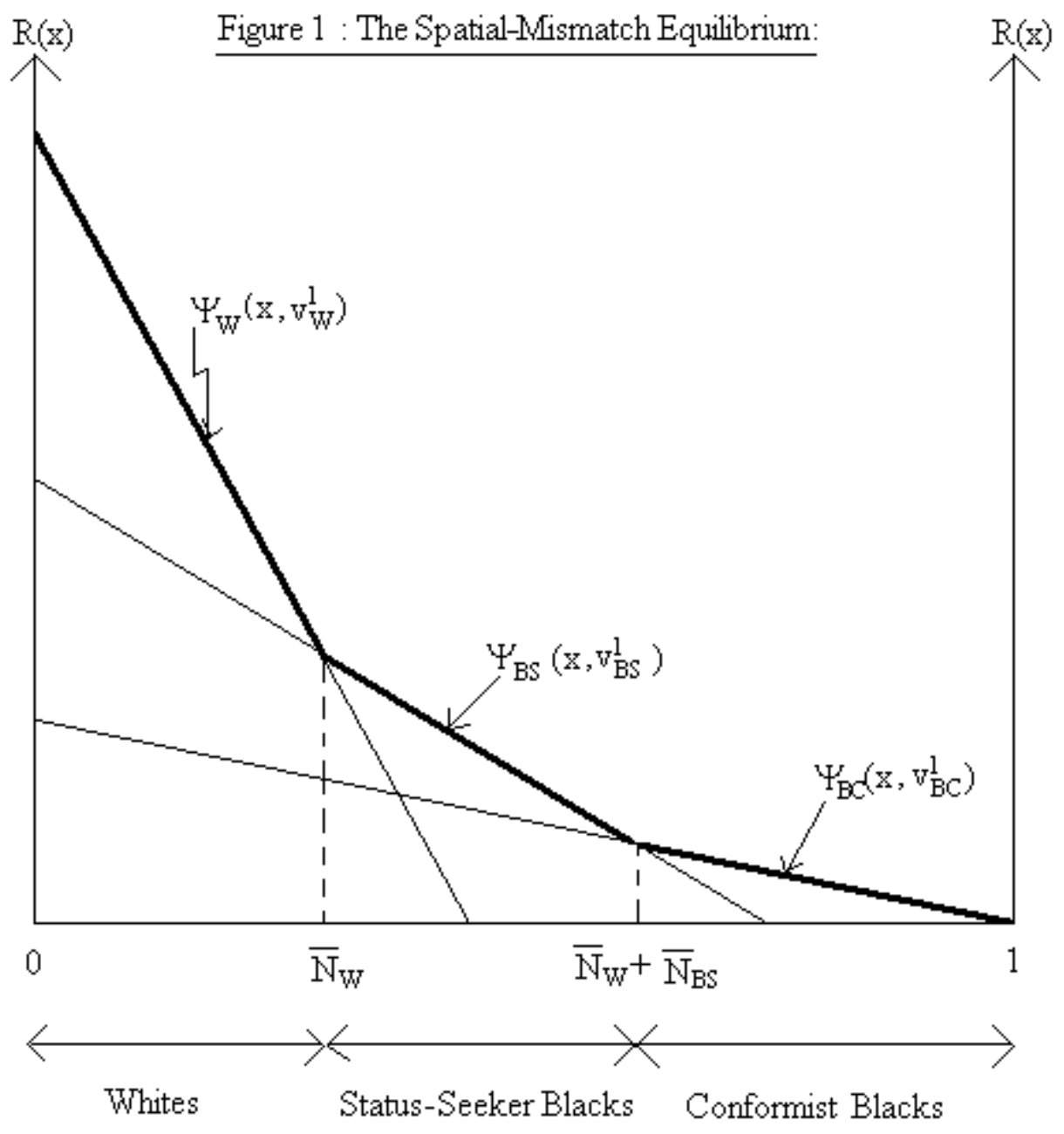


Figure 2: The Spatial-Matching Equilibrium:

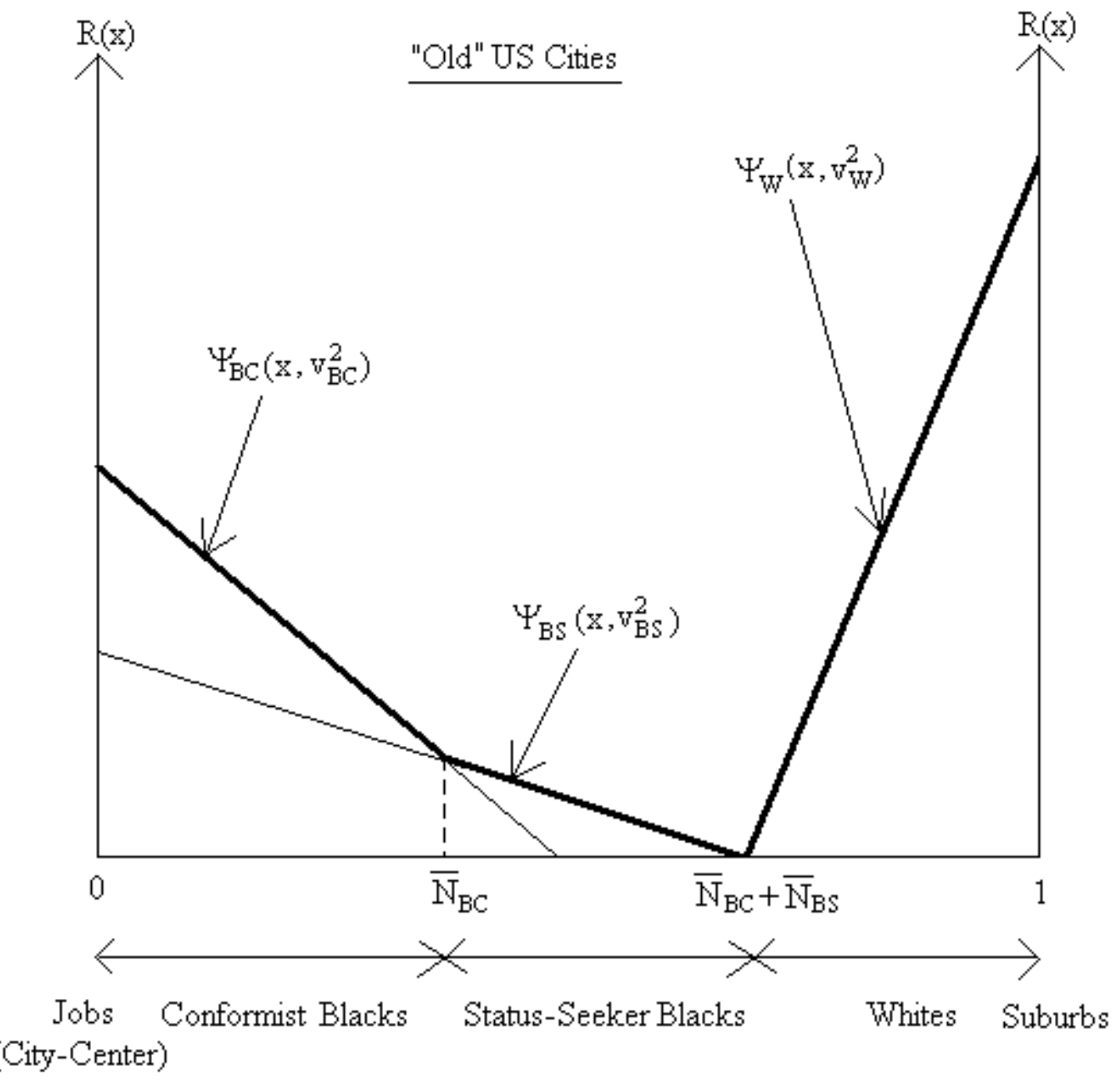




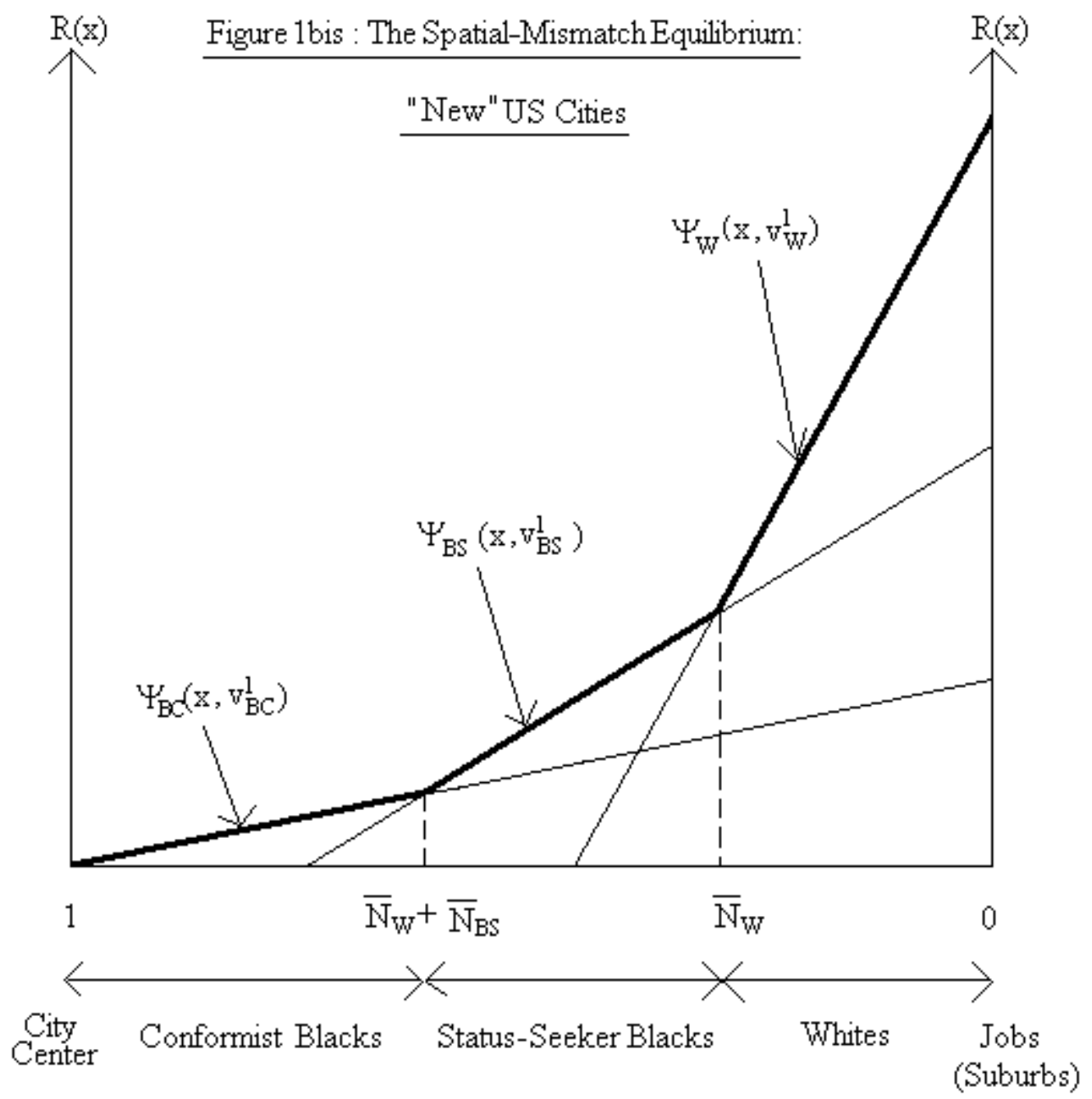




\section{IZA Discussion Papers}

\begin{tabular}{|c|c|c|c|c|}
\hline No. & Author(s) & Title & Area & Date \\
\hline 914 & $\begin{array}{l}\text { A. R. Cardoso } \\
\text { P. Portugal }\end{array}$ & $\begin{array}{l}\text { Bargained Wages, Wage Drift and the Design of } \\
\text { the Wage Setting System }\end{array}$ & 5 & $10 / 03$ \\
\hline 915 & $\begin{array}{l}\text { R. Hujer } \\
\text { C. Zeiss }\end{array}$ & $\begin{array}{l}\text { Macroeconomic Impacts of ALMP on the } \\
\text { Matching Process in West Germany }\end{array}$ & 6 & $10 / 03$ \\
\hline 916 & $\begin{array}{l}\text { S. C. Wolter } \\
\text { S. Mühlemann } \\
\text { J. Schweri }\end{array}$ & $\begin{array}{l}\text { Why Some Firms Train Apprentices and Many } \\
\text { Others Do Not }\end{array}$ & 5 & $10 / 03$ \\
\hline 917 & $\begin{array}{l}\text { R. Euwals } \\
\text { H. Roodenburg }\end{array}$ & $\begin{array}{l}\text { A Note on the Redistributive Effect of } \\
\text { Immigration }\end{array}$ & 1 & $10 / 03$ \\
\hline 918 & $\begin{array}{l}\text { V. Jakobsen } \\
\text { M. Rosholm }\end{array}$ & $\begin{array}{l}\text { Dropping out of School? A Competing Risks } \\
\text { Analysis of Young Immigrants' Progress in the } \\
\text { Educational System }\end{array}$ & 1 & $10 / 03$ \\
\hline 919 & M. Fertig & $\begin{array}{l}\text { The Impact of Economic Integration on } \\
\text { Employment - An Assessment in the Context of } \\
\text { EU Enlargement }\end{array}$ & 2 & $10 / 03$ \\
\hline 920 & $\begin{array}{l}\text { Ø. A. Nilsen } \\
\text { K. G. Salvanes } \\
\text { F. Schiantarelli }\end{array}$ & $\begin{array}{l}\text { Employment Changes, the Structure of } \\
\text { Adjustment Costs, and Plant Size }\end{array}$ & 1 & $11 / 03$ \\
\hline 921 & $\begin{array}{l}\text { P. Egger } \\
\text { M. Pfaffermayr } \\
\text { A. Weber }\end{array}$ & $\begin{array}{l}\text { Sectoral Adjustment of Employment: The Impact } \\
\text { of Outsourcing and Trade at the Micro Level }\end{array}$ & 2 & $11 / 03$ \\
\hline 922 & $\begin{array}{l}\text { J. Merz } \\
\text { D. Burgert }\end{array}$ & $\begin{array}{l}\text { Working Hour Arrangements and Working Hours } \\
\text { - A Microeconometric Analysis Based on } \\
\text { German Time Use Diary Data }\end{array}$ & 5 & $11 / 03$ \\
\hline 923 & $\begin{array}{l}\text { U. Dulleck } \\
\text { P. Frijters } \\
\text { R. Winter-Ebmer }\end{array}$ & $\begin{array}{l}\text { Reducing Start-Up Costs for New Firms: The } \\
\text { Double Dividend on the Labour Market }\end{array}$ & 5 & $11 / 03$ \\
\hline 924 & $\begin{array}{l}\text { A. P. Damm } \\
\text { M. Rosholm }\end{array}$ & $\begin{array}{l}\text { Employment Effects of Dispersal Policies on } \\
\text { Refugee Immigrants, Part I: Theory }\end{array}$ & 1 & $11 / 03$ \\
\hline 925 & $\begin{array}{l}\text { A. P. Damm } \\
\text { M. Rosholm }\end{array}$ & $\begin{array}{l}\text { Employment Effects of Dispersal Policies on } \\
\text { Refugee Immigrants, Part II: Empirical Evidence }\end{array}$ & 1 & $11 / 03$ \\
\hline 926 & $\begin{array}{l}\text { S. E. Black } \\
\text { P. J. Devereux } \\
\text { K. G. Salvanes }\end{array}$ & $\begin{array}{l}\text { Why the Apple Doesn't Fall Far: Understanding } \\
\text { Intergenerational Transmission of Human } \\
\text { Capital }\end{array}$ & 5 & $11 / 03$ \\
\hline 927 & $\begin{array}{l}\text { L. Goette } \\
\text { D. Huffman } \\
\text { E. Fehr }\end{array}$ & Loss Aversion and Labor Supply & 5 & $11 / 03$ \\
\hline 928 & $\begin{array}{l}\text { H. Selod } \\
\text { Y. Zenou }\end{array}$ & $\begin{array}{l}\text { Does City Structure Affect the Labor Market } \\
\text { Outcomes of Black Workers? }\end{array}$ & 3 & $1 / 03$ \\
\hline
\end{tabular}

An updated list of IZA Discussion Papers is available on the center's homepage www.iza.org. 